\title{
The Effect of Turbinate Injection of Botulinum Toxin A on the Symptoms of Idiopathic Rhinitis
}

\author{
Thiago Carvalho $^{10}$ Daniel Calduro Salgado ${ }^{10}$ Olavo de Godoy Mion ${ }^{10}$ \\ João Ferreira de Mello Junior ${ }^{10}$ Richard Louis Voegels ${ }^{10}$ \\ ${ }^{1}$ Department of Otorhinolaryngology, Faculdade de Medicina da \\ Universidade de São Paulo , São Paulo, SP, Brazil \\ Int Arch Otorhinolaryngol 2022;26(2):e191-e198. \\ Address for correspondence Thiago Carvalho, PhD student, \\ Faculdade de Medicina da Universidade de São Paulo - Departamento \\ de Otorrinolaringologia, São Paulo, SP, Brazil \\ (e-mail: thiagocarvalho@usp.br).
}

\begin{abstract}
Keywords

- rhinitis

- botulinum toxin

- nasal obstruction

- pruritus

- acoustic rhinometry

- therapeutics

Introduction Idiopathic rhinitis is a nonallergic and noninfectious rhinitis characterized mainly by nasal obstruction and rhinorrhea, resulting from an autonomic imbalance. Botulinum toxin type $A$ (BTX-A) demonstrated its action in reducing rhinorrhea and nasal obstruction when injected into the nasal turbinates or septum.

Objective To analyze the effects of intranasal BTX-A injection to control the symptoms of idiopathic rhinitis and its possible adverse effects.

Method Patients with idiopathic rhinitis were divided into two groups. Group A had 15 participants ( 8 female and 6 male), of ages from 47 to 84 years (mean 66.57 years), and these received $60 \mathrm{U}$ of Dysport (Ipsen Ltd, Maidenhead, Berkshire, UK) in each inferior nasal turbinate; group $B$ had 12 participants ( 1 male and 11 female), of ages from 50 to 76 years (mean 60 years), and they received $1 \mathrm{ml}$ of $0.9 \%$ saline. The individuals were reevaluated in the $1^{\text {st }}, 2^{\text {nd }}, 4^{\text {th }}, 8^{\text {th }}$, and $12^{\text {th }}$ weeks after injection by a questionnaire, accompanied by nasal inspiratory peak flow and acoustic rhinometry. Results Group A showed significant improvement, mainly regarding the symptoms of sneezing/itching and nasal obstruction, over time and when compared to group B. Acoustic rhinometry confirmed the improvement in nasal obstruction. There was no relationship between the nasal peak flow data and the nasal obstruction score. No major adverse effects have been reported.

Conclusion The injection of botulinum toxin in the inferior nasal turbinates of patients with idiopathic rhinitis reduces the symptoms of sneezing, itching, nasal obstruction, and runny nose without significant adverse effects, suggesting that it is an option in the treatment of these patients.
\end{abstract}

\section{Introduction}

Rhinitis is defined as inflammation of the nasal mucosa, which is characterized by nasal discharge, itching, sneezing, and nasal obstruction and affects approximately $30 \%$ of the population. ${ }^{1,2}$ Classically, rhinitis is classified as allergic, infectious, nonallergic noninfectious, or mixed rhinitis. ${ }^{2,3}$ Idiopathic rhinitis, known in the past as vasomotor rhinitis, is a type of non-allergic and noninfectious rhinitis, and it is not related to systemic diseases, structural injuries, or drug abuse. Therefore, its diagnosis is based on the exclusion of all other groups of rhinitis, through clinical history, allergic test, nasal cytological examination and rhinoscopy. ${ }^{2-4}$ The main symptoms are nasal obstruction and received

August 6, 2020

accepted

December 29, 2020

published online

August 13, 2021
DOI https://doi.org/ 10.1055/s-0041-1730307. ISSN 1809-9777.

\footnotetext{
(c) 2021. Fundação Otorrinolaringologia. All rights reserved. This is an open access article published by Thieme under the terms of the Creative Commons Attribution-NonDerivative-NonCommercial-License, permitting copying and reproduction so long as the original work is given appropriate credit. Contents may not be used for commercial purposes, or adapted, remixed, transformed or built upon. (https://creativecommons.org/ licenses/by-nc-nd/4.0/) Thieme Revinter Publicações Ltda., Rua do Matoso 170, Rio de Janeiro, RJ, CEP 20270-135, Brazil
} 
Carvalho et al.

rhinorrhea, with no evidence of allergic sensitization, which can be perennial/persistent and/or with recognized triggering factors.

Idiopathic rhinitis still does not have its pathophysiology completely elucidated; however, some studies suggest the existence of an autonomic imbalance with inhibition of the sympathetic nervous system response in the nose and hyperactivity of the parasympathetic system leading to nasal obstruction and increased glandular secretion.,6 Other mechanisms found in idiopathic rhinitis include the participation of the nonadrenergic, noncholinergic system (NANC). Nonspecific stimuli in the nasal mucosa can activate nonmyelinated sensory C-fibers, releasing neuropeptides, thus contributing to the symptoms of patients with idiopathic rhinitis. ${ }^{6}$ Some authors suggest that nasal hyperreactivity may be related to the release of substance $P$ through trigeminal terminations, leading to vasodilation and increased vascular permeability. ${ }^{7}$

The treatment of idiopathic rhinitis includes long-term use of decongestants, intranasal ipratropium bromide, and antihistamines, and there are some potential side effects. Nasal steroids may be a treatment option, but their effectiveness is not consistent. ${ }^{3}$ Azelastine has shown a reduction in nasal sensitivity to odors in patients with nonallergic rhinitis. ${ }^{8}$ Capsaicin can be used in the treatment of idiopathic rhinitis, although there is still no standardization regarding its form of use. ${ }^{3,9}$ The vidian neuroctomy nerve can be used to treat refractory rhinitis, especially nonallergic rhinitis; nonetheless, it has a high rate of complications, especially when not performed by the endonasal route. ${ }^{10}$

Botulinum toxin is a neurotoxin produced by Clostridium botulinum that inhibits the release of acetylcholine from presynaptic nerve fibers. There are seven antigenic types of botulinum toxin, divided from $A$ to $G .{ }^{11}$ Due to its great anticholinergic action at the neuromuscular junction, botulinum toxin type A (BTX-A) is used in a wide spectrum of conditions characterized by muscle hyperactivity or by increased glandular secretion. ${ }^{11,12}$ Botulinum toxin has been used in the treatment of several non-cosmetic conditions in the head and neck area, such as laryngeal dystonia, headache, cervical dystonia, masticatory myalgia, drooling, temporomandibular joint disorders, bruxism, blepharospasm, and hemifacial spasm, with level 1 evidence of effectiveness. ${ }^{12}$

The effect of BTX-A on glandular secretion is well demonstrated through its use in Frey syndrome, hyperhidrosis, and sialorrhea. ${ }^{13}$ Some studies have shown the action of BTX-A on the nasal mucosa with reduced rhinorrhea and nasal obstruction, suggesting an important role in the control of symptoms of rhinitis when injected into the nasal turbinates or septum. The aim of the present study was to analyze the effects of intranasal injection of BTX-A on the control of idiopathic rhinitis symptoms, as well as to evaluate some objective patterns such as nasal peak flow and acoustic rhinometry and possible adverse effects.

\section{Method}

The study was approved by the research ethics committee under the number 0333/09, and all individuals received and signed a free and informed consent form. Patients with
Table 1 Inhaled antigens tested

\begin{tabular}{|l|l|}
\hline Mites & - Dermatophagoides pteronyssinus \\
& - Dermatophagoides farinae \\
& - Blomia tropicalis \\
\hline Mold & - Alternaria alternata \\
& - Cladosporium herbarum \\
& - Aspergillus fumigatus \\
\hline Cockroaches & - Blatella germânica \\
& - Periplaneta americana \\
\hline Animal antigens & - Canis familiaris \\
& - Felis domesticus \\
\hline Pollens & - Phleum pratense \\
& - Lolium perenne \\
& - Dactylis glomerata \\
& - Festuca pratensis \\
\hline
\end{tabular}

clinical symptoms suggestive of idiopathic rhinitis were selected. All patients underwent nasal endoscopy, immediate hypersensitivity skin test (prick test) with common inhaled antigens in our environment, listed on - Table $\mathbf{1}$, and nasal cytological examination.

The inclusion criteria were:

A) Patients over 18 years old who signed the free and informed consent form and understood the explanation of the study, carried out by the researcher himself.

B) Patients of both sexes, regardless of race.

C) Patients diagnosed with idiopathic rhinitis for at least 1 year, that is, patients in whom other rhinitis etiologies (allergic rhinitis, non-allergic eosinophilic, medication, hormonal, drug and occupational) were excluded through clinical history, physical examination, nasal cytological examination with eosinophils below $2 \%$ and skin test for immediate hypersensitivity to negative inhalants.

The exclusion criteria were:

A) Patients with other nasal anatomical abnormalities, such as nasal polyposis or obstructive nasal septum deviation.

B) Patients with acute or chronic rhinosinusitis.

C) Patients with severe systemic diseases, glaucoma, or prostatic hypertrophy that can be aggravated by anticholinergic therapy.

D) Patients with positive immediate hypersensitivity skin test for inhalants, and nasal cytological exam with eosinophilia greater than $2 \%$.

E) Patients who received rhinitis medications before the immediate hypersensitivity skin test for inhalants according to - Table 2.

F) Patients with possibility of pregnancy.

The patients were randomly divided into two groups, the group that received BTX-A and the control group. Each BTX-A bottle(Dysport, Ipsen Ltd, Maidenhead, Berkshire, UK) contains a $500 \mathrm{U}$ dose, which was diluted in saline. After topical nasal injection of lidocaine with soaked cotton, a $60 \mathrm{U}$ dose of Dysport was injected, equivalent to $20 \mathrm{U}$ of BTX-A Botox, diluted in $1 \mathrm{ml}$ and divided into the head and body of the 
Table 2 Drugs that affect the efficiency of skin prick tests

\begin{tabular}{|c|c|c|c|}
\hline & \multicolumn{3}{|l|}{ Supression } \\
\hline & Degree & $\begin{array}{l}\text { Duration } \\
\text { (days) }\end{array}$ & $\begin{array}{l}\text { Clinical } \\
\text { significance }\end{array}$ \\
\hline \multicolumn{4}{|c|}{$\mathrm{H} 1$ antihistamines } \\
\hline Cetirizine & ++++ & $3-10$ & Yes \\
\hline Chlorferinamine & ++ & $1-3$ & Yes \\
\hline Desloratadine & ++++ & $3-10$ & Yes \\
\hline Ebastine & ++++ & $3-10$ & Yes \\
\hline Hydroxyzine & +++ & $1-10$ & Yes \\
\hline $\begin{array}{l}\text { Levocabastine } \\
\text { (topical) }\end{array}$ & Possible & & Yes \\
\hline Levocetirizine & ++++ & $3-10$ & Yes \\
\hline Loratadine & ++++ & $3-10$ & Yes \\
\hline Mequitazine & ++++ & $3-10$ & Yes \\
\hline Mizolastine & ++++ & $3-10$ & Yes \\
\hline Promethazine & ++ & $1-3$ & Yes \\
\hline Ketotifen & ++++ & $>5$ & Yes \\
\hline \multicolumn{4}{|c|}{$\mathrm{H} 2$ antihistamines } \\
\hline Imipramines & ++++ & $>10$ & Yes \\
\hline Phenothiazines & ++ & $?$ & Yes \\
\hline \multicolumn{4}{|c|}{ Glucocorticosteroids } \\
\hline $\begin{array}{l}\text { Systemic, } \\
\text { short period }\end{array}$ & 0 & & \\
\hline $\begin{array}{l}\text { Systemic, } \\
\text { long period }\end{array}$ & Possible & & Yes \\
\hline Inhaled & 0 & & \\
\hline Topic (skin) & 0 to ++ & & Yes \\
\hline Cromolyn & 0 & & \\
\hline \multicolumn{4}{|l|}{$\beta 2$ agonists } \\
\hline Formoterol & Unknown & & \\
\hline Dopamine & Unknown & & \\
\hline Clonidine & ++ & & \\
\hline Montelukast & 0 & & \\
\hline
\end{tabular}

inferior nasal turbinate of each nasal cavity in group A (total of $40 \mathrm{U} /$ subject). In group B, after topical nasal application of lidocaine, $1 \mathrm{ml}$ of $0.9 \%$ saline solution was injected, divided into the head and body of the inferior nasal turbinate of each nasal cavity. Simple randomization and preparation of the syringe were performed by another professional who performed the injection. Neither the professional who performed the injection nor the research subjects knew the syringe content.

The individuals were reevaluated in the $1^{\text {st }}, 2^{\text {nd }}, 4^{\text {th }}, 8^{\text {th }}$ and $12^{\text {th }}$ weeks after the injection of BTX-A, according to the schedule detailed in - Table 3. At each visit, they answered a questionnaire about the symptoms (nasal obstruction, rhinorrhea, pruritus, and sneezing) which were classified from 0 to 3 , according to the score of signs and symptoms proposed by Mello Jr., ${ }^{14}$ described in - Table 4, accompanied by nasal inspiratory peak flow and acoustic rhinometry. The professional who performed the evaluations did not have the information of which group the subject belonged to.

An Eccovision Acoustic Rhinometry System (Eccovision Nasal Version 4.40; Hood Laboratories, Pembroke, MA, USA) was used. The measurements were made according to the guidelines recommended by the Standardization Committee on Objective Assessment of the Nasal Airway. ${ }^{15}$ The nose piece did not enter the vestibule.

The nasal inspiratory peak flow was measured 3 consecutive times with a 1-minute interval between them. The examination technique consisted of measuring the nasal inspiratory flow of the seated patient, with the device positioned on the face, completely covering the nose through a small, well-sealed mask connected to a plastic cylinder through which the forced inspired air passes. The measurement was performed on a scale with the mark on the cylinder surface that varies between 30 to 370 liters/minute.

Statistical analyses were performed using the R software (R Foundation for Statistical Computing, Vienna, Austria) and GraphPad Prism (GraphPad Software, Inc, La Jolla, CA, USA). The Mann-Whitney test was used to compare the groups, and linear regression was used to assess the evolution of symptoms over time. The repeated measures test was used to analyze the changes within and between the groups. Multivariate analyses were conducted where needed. A $p$-value of $<0.05$ was considered significant.

\section{Results}

Group A (BTX-A) had 15 participants (8 female and 6 male), of ages from 47 to 84 (mean 66.57 years). Group B (control) had 12 participants ( 1 male and 11 female) of ages from 50 to 76 (mean 60 years), presented in - Table 5. We noticed a

Table 3 Schedule

\begin{tabular}{|l|l|l|l|l|l|l|}
\hline & Physical examination & Skin prick test & Peak flow & Nasal cytology & VAS & Acoustic rhinometric \\
\hline Day 0 & + & + & + & + & + & + \\
\hline Week 1 & + & & + & & + & + \\
\hline Week 2 & + & & + & & + & + \\
\hline Week 4 & + & & + & & + & + \\
\hline Week 8 & + & & + & & + & + \\
\hline Week 12 & + & & + & & + & + \\
\hline
\end{tabular}


Table 4 Score of nasal signs and symptoms

\begin{tabular}{|c|c|}
\hline Symptoms & Signs \\
\hline $\begin{array}{l}\text { Sneezing/itching } \\
0 \text { - Absent } \\
1-1 \text { to } 4 \text { per day/occasional itching } \\
\text { 2- } 5 \text { to } 10 \text { per day/sporadic itching for } 30 \text { minutes } \\
\text { 3- } 11 \text { or more/interferes with sleep and/or concentration } \\
\text { Runny nose } \\
\text { 0- Absent } \\
\text { 1- Cleaning } 1 \text { to } 4 \text { times a day } \\
\text { 2- Cleaning } 5 \text { to } 10 \text { times a day } \\
\text { 3- Constant cleaning } \\
\text { Nasal obstruction } \\
0 \text { - Absent } \\
\text { 1- Small and not disturbing } \\
\text { 2- Mouth breathing most of the day } \\
\text { 3- Does not breathe through the nose / } \\
\text { interferes with sleep, smell or voice } \\
\text { Retro-nasal secretion } \\
0 \text { - Absent } \\
\text { 1- Sensation of secretion in the throat } \\
\text { 2- Frequent throat cleaning } \\
\text { 3- Cough and discomfort when speaking oropharynx }\end{array}$ & $\begin{array}{l}\text { Nasal secretion } \\
0 \text { - Absent } \\
\text { 1- The mucosa appears moist } \\
\text { 2- Visible secretion in the turbinates or nasal floor } \\
\text { 3- Profuse/draining } \\
\text { Color of the nasal turbinates } \\
\text { 0- Rosy } \\
\text { 1- Reddish/pale pink } \\
\text { 2- Red/pale } \\
\text { 3- Anemic/bluish } \\
\text { Edema of the nasal turbinate } \\
\text { 0- Absent } \\
\text { 1- Hypertrophy of the inferior or middle turbinate with small nasal block } \\
\text { 2- Congestion compromising breathing in one or both nasal cavities } \\
\text { 3- Congestion preventing breathing in one or both nasal cavities } \\
\text { Posterior wall of the oropharynx } \\
\text { 0- Normal } \\
\text { 1- Discreetly red } \\
\text { 2- Hyperemic and apparent lymphoid follicles } \\
\text { 3- Visible mucus }\end{array}$ \\
\hline
\end{tabular}

Adapted from Mello Jr 2002.

Table 5 Sample descriptive

\begin{tabular}{|c|l|l|l|}
\hline & $\begin{array}{l}\text { Group A } \\
(\mathbf{n = 1 5 )}\end{array}$ & $\begin{array}{l}\text { Group B } \\
(\mathbf{n = 1 2})\end{array}$ & $p$-value \\
\hline Gender & & & \\
\hline Female & 8 & 11 & $*$ \\
\hline Male & 6 & 1 & \\
\hline Age $^{\text {a }}$ (years) & $47-84$ & $50-76$ & \\
\hline Mean $^{\text {b }}$ & $66.57 \pm 10.2$ & $60 \pm 7.88$ & 0.0996 \\
\hline
\end{tabular}

${ }^{\mathrm{a}}$ Teste de Wilcoxon.

bData are presented as mean \pm standard deviation.

*As the contingency table has a value less than 5 , it was not possible to do the chisquare test.

difference between the groups in terms of gender but not in terms of ages. As the contingency table has a value $<5$, it was not possible to perform the chi-squared test. However, linear regression shows that age and gender are not significant determining the score difference between the groups in the $12^{\text {th }}$ week $(p$-value $=0.0241$, adjusted R-squared $=0.2745)$.

The two groups were similar with regards to nasal signs and symptoms score at baseline, as shown in - Table $\mathbf{6}$. The symptoms showed improvement after 1 week, but the statistical difference between the 2 groups appeared only in the $2^{\text {nd }}$ week. The improvement in the score was due to the symptoms of sneezing/itching and runny nose. In the $12^{\text {th }}$ week, group A still showed improvement in scores when compared to baseline and to the control group.

Graph 1 shows the evolution of total symptoms throughout the study, and it was found that the group that received the injection of botulinum toxin showed a statistically significant improvement, according to the Mann-Whitney test and presented in - Table $\mathbf{6}$. Comparison of each item of the nasal signs and symptoms score from baseline to the $12^{\text {th }}$
Table 6 Symptom score from baseline to $12^{\text {th }}$ Week.

\begin{tabular}{|l|l|l|l|}
\hline Week & $\begin{array}{l}\text { TXB-A } \\
\mathbf{N}=\mathbf{1 5}\end{array}$ & $\begin{array}{l}\text { Control } \\
\mathbf{N}=\mathbf{1 2}\end{array}$ & p-value \\
\hline Baseline & $10.9 \pm 3.65$ & $10.9 \pm 2.31$ & 0.9892 \\
\hline 1 & $8.87 \pm 4.21$ & $8.73 \pm 2.41$ & 0.9225 \\
\hline 2 & $6.50 \pm 3.03$ & $9.33 \pm 2.87$ & 0.0121 \\
\hline 4 & $6.14 \pm 2.44$ & $8.64 \pm 2.46$ & 0.0087 \\
\hline 8 & $6.08 \pm 2.47$ & $7.75 \pm 2.05$ & 0.0695 \\
\hline 12 & $5.53 \pm 1.68$ & $9.00 \pm 2.93$ & 0.0008 \\
\hline$p$-value ${ }^{\mathrm{b}}$ & $<0.001$ & $<0.001$ & \\
\hline$p$-value $^{\mathrm{c}}$ & 0.0252 & & \\
\hline
\end{tabular}

Data are presented as mean \pm standard deviation.

${ }^{a}$ Mann-Whitney test.

${ }^{b}$ Repeated measure within group.

${ }^{\mathrm{c}}$ Repeated measure between group.

week in the 2 groups is presented in -Table 7. The symptoms of sneezing/itching and nasal obstruction showed significant improvement when compared to the control group, shown in Graphs 2 and 3. In the botulinum toxin group, we observed an important improvement in rhinorrhea over 12 weeks. However, when we analyzed the placebo group using the Mann-Whitney test $(p=0.048)$, the statistical difference appeared only in the $12^{\text {th }}$ week, represented in Graph 4. There was no difference between the groups nor over the 12 weeks in the score of retro nasal secretion.

Acoustic rhinometry confirmed the improvement in nasal obstruction over the 12 weeks $(p=0.002)$, even when compared to the control group, shown after the $2^{\text {nd }}$ week $(p=0.014)$. There was no relationship between the nasal peak flow data and the nasal obstruction score. No major adverse effects were reported, only mild burning during 


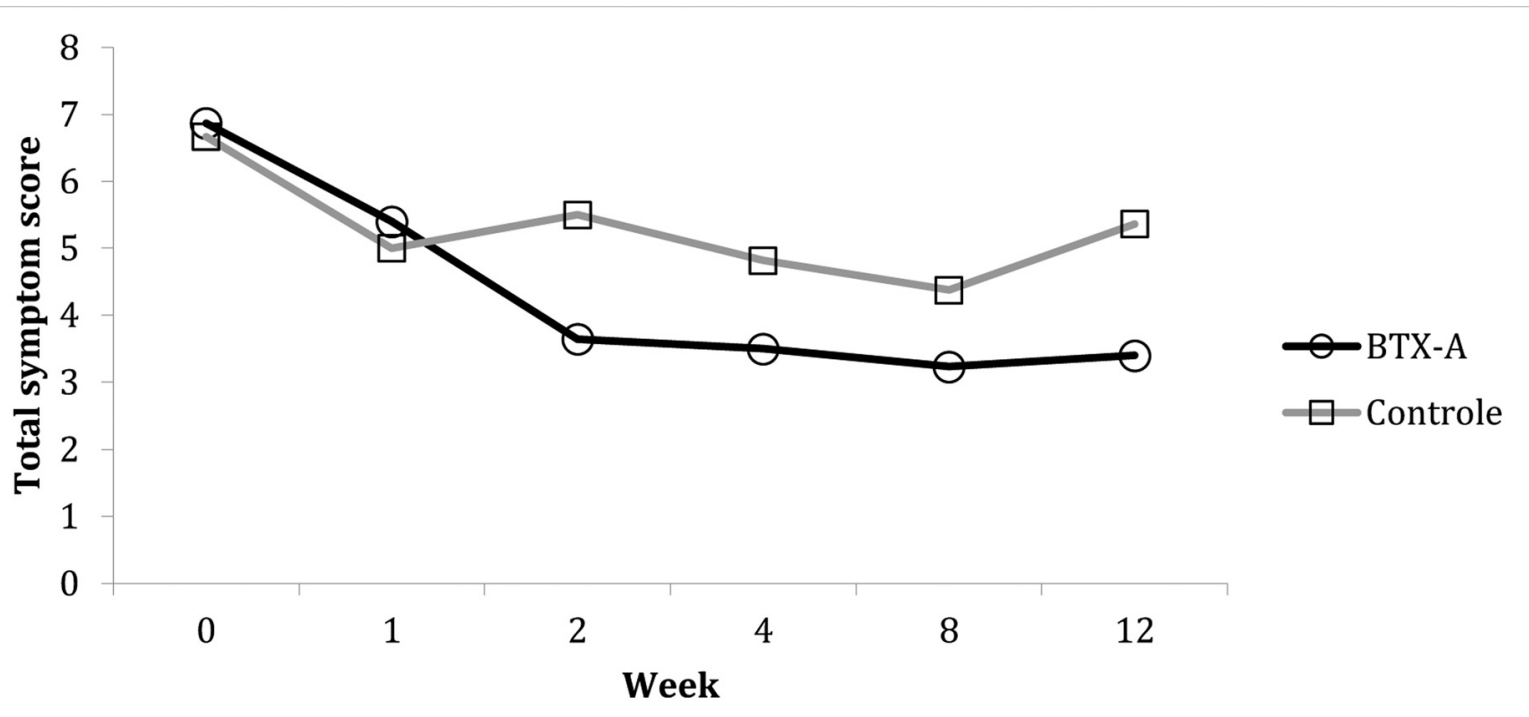

Graph 1 Comparison of the total symptom score between the group that received BTX-A and the control group over the 12 weeks.

Table 7 Comparison of each item of nasal signs and symptoms score from baseline to the $12^{\text {th }}$ Week in the two groups.

\begin{tabular}{|c|c|c|c|c|c|c|c|}
\hline & & \multicolumn{2}{|l|}{ BTX-A } & \multirow[t]{3}{*}{$p^{*}$} & \multirow{2}{*}{\multicolumn{2}{|c|}{$\begin{array}{l}\text { Control } \\
N=12\end{array}$}} & \multirow[t]{3}{*}{$p^{*}$} \\
\hline & & \multicolumn{2}{|l|}{$N=15$} & & & & \\
\hline & & Baseline & $12^{\text {th }}$ Week & & Baseline & $12^{\text {th }}$ Week & \\
\hline \multirow[t]{4}{*}{ Symptom } & Sneezing/itching & $1.87 \pm 1.13$ & $0.87 \pm 0.64$ & 0.092 & $1.92 \pm 0.90$ & $1.82 \pm 0.98$ & 0.897 \\
\hline & Runny nose & $2.53 \pm 0.83$ & $1.13 \pm 0.64$ & $<0.001$ & $2.17 \pm 1.03$ & $1.82 \pm 0.75$ & 0.270 \\
\hline & Nasal Obstruction & $1.20 \pm 1.15$ & $0.40 \pm 0.51$ & $<0.05$ & $1.42 \pm 1.00$ & $0.82 \pm 0.98$ & 0.147 \\
\hline & Retro-nasal secretion & $1.27 \pm 1.03$ & $1.00 \pm 0.85$ & 0.4822 & $1.17 \pm 0.83$ & $0.91 \pm 0.54$ & 0.490 \\
\hline Total (symptoms) & & $6.47 \pm 2.50$ & $3.40 \pm 1.30$ & $<0.001$ & $6.67 \pm 1.44$ & $5.36 \pm 2.29$ & 0.127 \\
\hline \multirow[t]{4}{*}{ Signs } & $\begin{array}{l}\text { Color of the nasal } \\
\text { turbinates }\end{array}$ & $1.87 \pm 0.52$ & $1.27 \pm 0.46$ & $<0.01$ & $1.83 \pm 0.39$ & $1.82 \pm 0.40$ & 0.963 \\
\hline & $\begin{array}{l}\text { Edema of the nasal } \\
\text { turbinate }\end{array}$ & $1.07 \pm 0.70$ & $0.2 \pm 0.41$ & $<0.001$ & $1.00 \pm 0.60$ & $0.82 \pm 0.40$ & 0.447 \\
\hline & Nasal secretion & $0.67 \pm 0.62$ & $0.40 \pm 0.51$ & 0.2396 & $0.83 \pm 0.58$ & $0.64 \pm 0.67$ & 0.422 \\
\hline & $\begin{array}{l}\text { Posterior wall of } \\
\text { the oropharynx }\end{array}$ & $0.47 \pm 0.52$ & $0.27 \pm 0.46$ & 0.2745 & $0.58 \pm 0.67$ & $0.36 \pm 0.50$ & 0.459 \\
\hline Total (signs) & & $4.07 \pm 1.44$ & $2.13 \pm 0.99$ & $<0.001$ & $4.25 \pm 1.42$ & $3.64 \pm 1.12$ & 0.343 \\
\hline Total score: & & $10.53 \pm 3.11$ & $5.53 \pm 1.68$ & $<0.001$ & $10.92 \pm 2.31$ & $9.00 \pm 2.93$ & 0.087 \\
\hline
\end{tabular}

Data are presented as mean \pm standard deviation.

BXT-A, botulinum toxin A.

*Wilcoxon test.

injection in four patients and mild self-limited bleeding in two patients.

\section{Discussion}

We demonstrated a decrease in nasal symptoms of patients with idiopathic rhinitis after the injection of botulinum toxin in the inferior nasal turbinates without showing significant adverse effects. Botulinum toxin type $A$ has been tested for idiopathic rhinitis since $1998,{ }^{16}$ under different regimens, all with favorable results. The topical route uses a greater amount of toxin (20-50U/nostril x 4-30U/nostril) and does not allow quantifying the medication absorbed. When the injectable route was used, the sites chosen were the inferior turbinate, the middle turbinate and the anterior portion of the septum. Braun et al., in 2012, carried out a pilot study with 5 patients who received $80 \mathrm{U}$ of BTX applied to the septum, obtaining symptom improvement without significant discomfort during injection.

Considering that the anterior portion of the inferior turbinate has more mucous glands, and the anterior portion of the septum has more serous glands, ${ }^{17}$ the hypothesis of different results was raised according to the application site. Abtahi et al., in 2013, observed an improvement in symptoms 


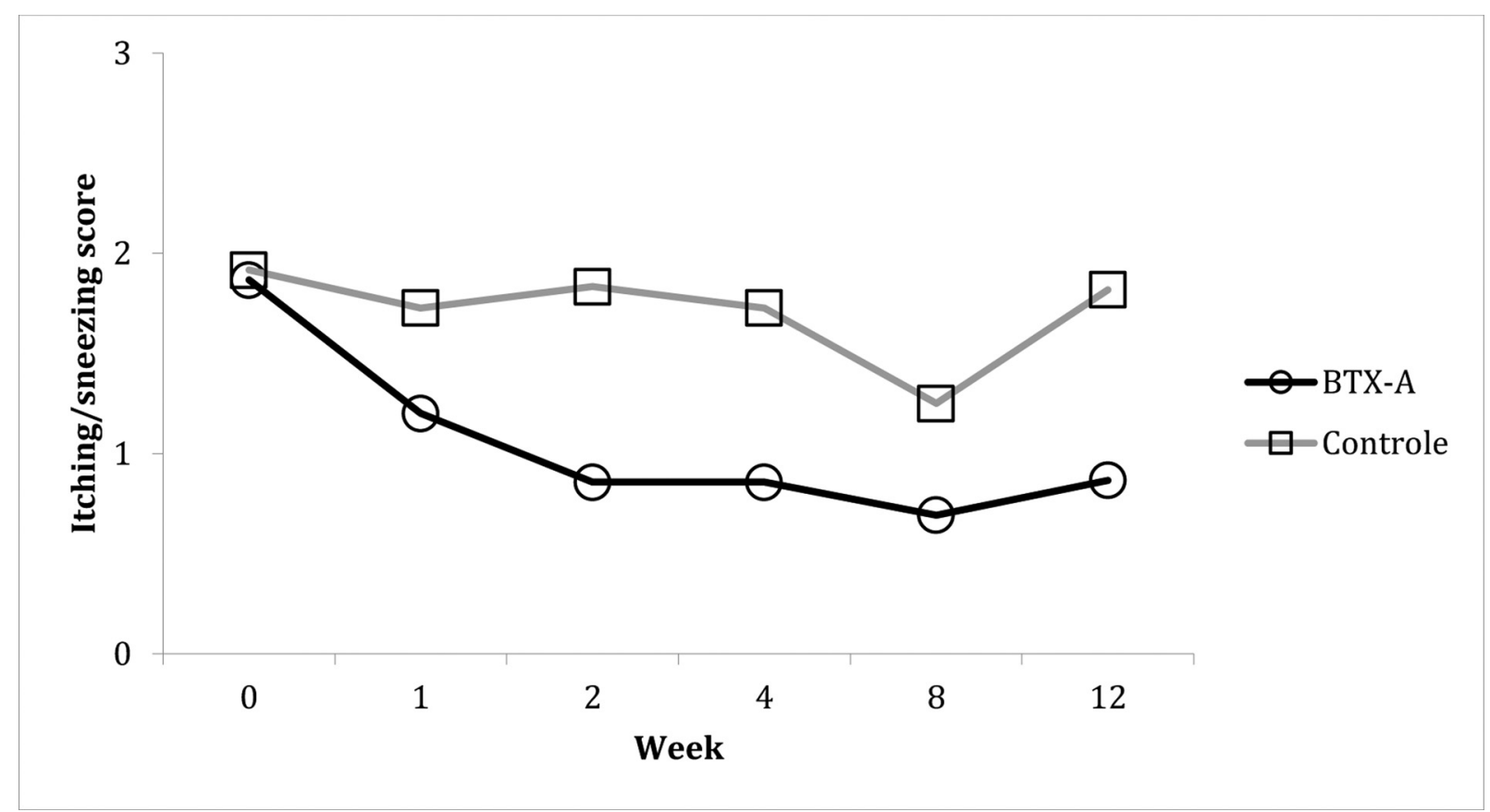

Graph 2 Comparison between the group that received BTX-A and the control group regarding itching and sneezing over the 12 weeks.

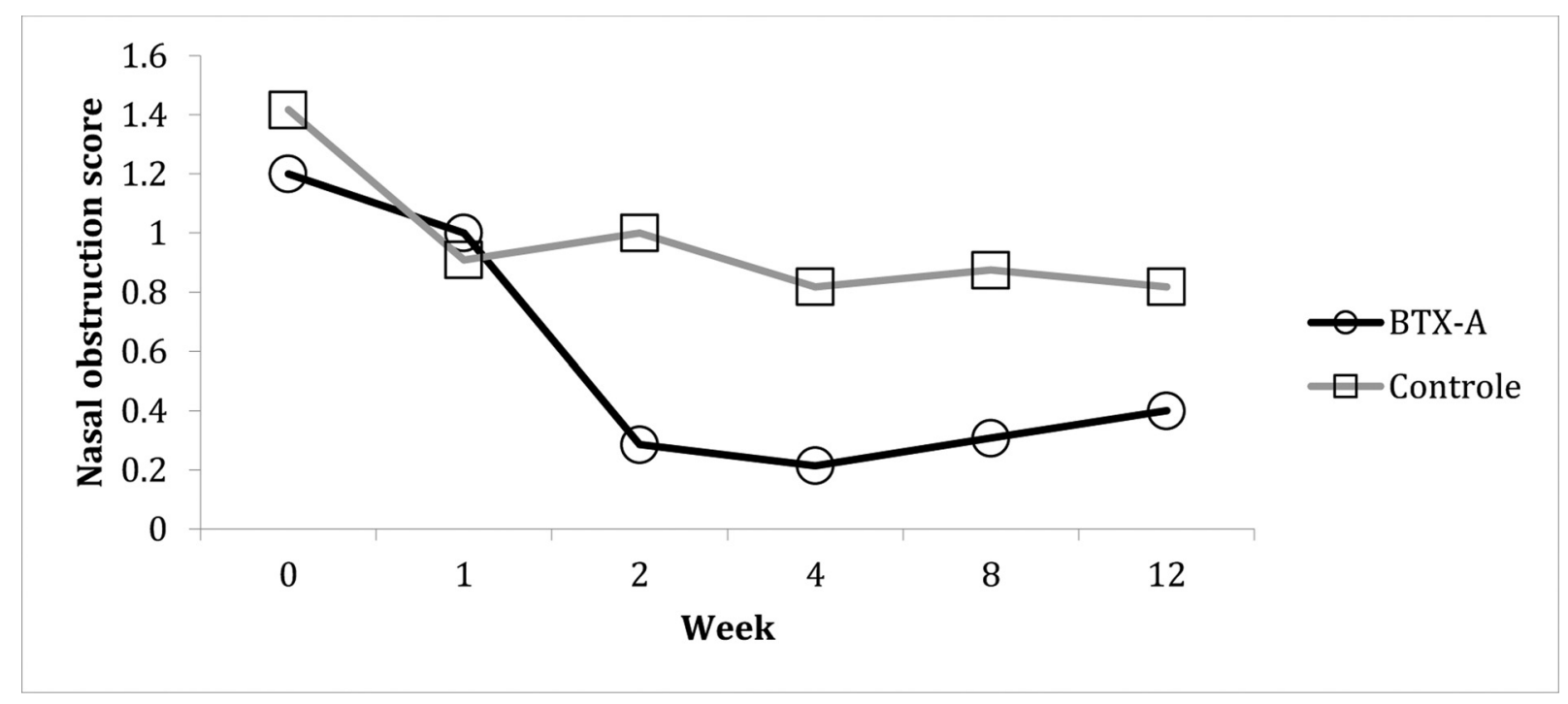

Graph 3 Comparison between the group that received BTX-A and the control group regarding nasal obstruction over the 12 weeks.

both in the group that received the injection in the turbinates and in the septum, showing that there was no difference in effectiveness. However, the occurrence of adverse effects (epistaxis) reported was greater when the application was in the turbinate. The same author considered septal injection to be safer and technically easier. ${ }^{18}$ Mozafarinia et al., in 2015, also suggested that the subperichondrial septal injection could have a more prolonged effectiveness due to the lower clearance of the drug, obtaining the peak of symptom improvement in the $4^{\text {th }}$ week, with gradual return to the initial levels in the $12^{\text {th }}$ week. Nevertheless, these results were not superior to the studies that applied the substance to the inferior turbinates, ${ }^{19,20}$ including the present study, in which the effects lasted until the $12^{\text {th }}$ week.
The symptoms involved in rhinitis are assessed with subjective tests using symptom scores and visual analog scales. Rohrbach et al., in their 2001 case report, counted the tissues used to assess rhinorrhea and rhinomanometry to quantify nasal permeability, noting an improvement in all parameters. $^{21}$ In 2009, these same authors, now with 17 patients, used the tissue count and obtained an improvement in the complaint of rhinorrhea and a decrease in the number of tissues. ${ }^{20}$ The other studies used symptom scales to assess the subjects' evolution. The improvement in nasal obstruction has been observed in most studies, which has led us to introduce two objective measures of nasal permeability: nasal peak flow and acoustic rhinometry. In the present study, a significant improvement in nasal obstruction was 


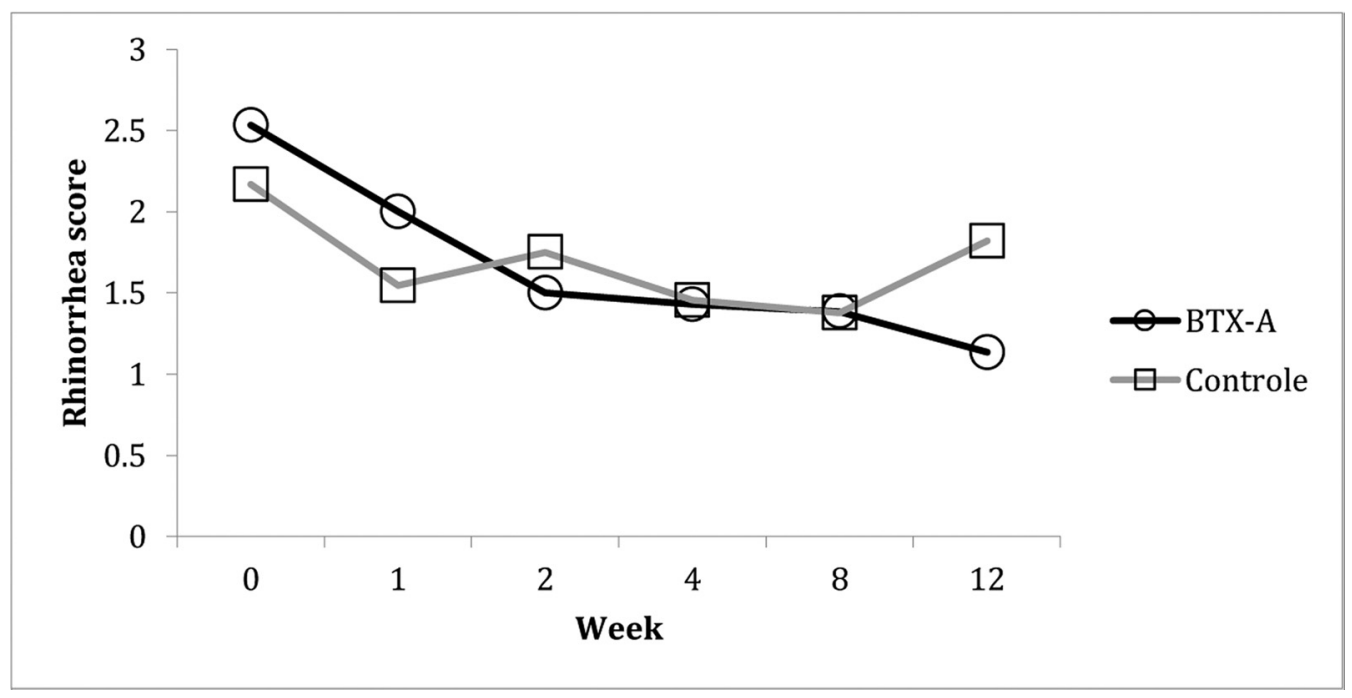

Graph 4 Comparison between the group that received BTX-A and the control group regarding rhinorrhea over the 12 weeks.

observed, confirmed by acoustic rhinometry. This improvement in nasal obstruction can be attributed to the parasympathetic nervous system block, a greater manifestation of sympathetic stimuli (vasoconstriction) resulting in a decrease in the volume of the turbinates.

We observed improvement in other symptoms such as itching and sneezing, which also occurred in most studies. In 1998, Kim et al. injected $4 \mathrm{U}$ of BTX-A per nostril, observing a reduction in rhinorrhea, but it did not improve nasal obstruction and sneezing. ${ }^{16}$ Unal et al., in 2003, conducted a randomized, placebo-controlled study with 34 patients that showed improvement in sneezing and itching only in the first 2 weeks, using 20 and 30 U BTX-A infiltration. ${ }^{22}$ In 2006, a randomized, placebo-controlled study was conducted in 30 patients with idiopathic rhinitis divided into 2 groups, 1 and 2, that received infiltration of 5 and $10 \mathrm{U}$ of BTX-A respectively, in which only group 2 showed improvement in nasal itching for 8 weeks. ${ }^{23}$ The effect on sneezing and itching may be related to the dose applied.

Comparison with other medications has shown the superiority of botulinum toxin. In 2008, a prospective, randomized, placebo-controlled study of 38 patients with idiopathic rhinitis compared the effectiveness of applying BTX-A ( 5 U per nostril) with the use of topical nasal ipratropium bromide and observed an improvement in symptoms and duration of similar effect in both groups. ${ }^{24}$ However, botulinum toxin showed a more comfortable dosage, with a single dose and lasting 8 to 12 weeks, while ipratropium bromide requires 2 to 3 daily applications and is not available in Brazil. Still in 2008, Yang et al. showed better results when compared to injectable triamcinolone in the inferior turbinates. ${ }^{19}$

Allergic rhinitis patients have also shown significant improvement in symptoms after receiving botulinum toxin. In 2003, a randomized, placebo-controlled study of 34 patients with allergic rhinitis showed improvement in rhinorrhea, nasal obstruction, sneezing and itching using 20 and $30 \mathrm{U}$ BTX-A infiltration. ${ }^{22}$ In 2008, another study compared the infiltration of $25 \mathrm{U}$ of BTX-A in each nostril with the infiltration of triamcinolone in 39 patients with allergic rhinitis and observed a significant improvement in rhinorrhea and nasal obstruction in the BTX-A group, including superior to that of steroid. $^{19}$ In 2013, Hashemi et al. compared the effects of applying intranasal BTX-A with the use of $10 \mathrm{mg} /$ day cetirizine in patients with allergic rhinitis and observed similar improvement in symptoms in both groups. However, there was a high rate of drowsiness (44\%) in the group that received cetirizine. ${ }^{25}$ Abtahi et al., in 2013, demonstrated an improvement in nasal symptoms after the injection of 40U of intranasal BTX-A (Dysport) in patients with allergic rhinitis, both when applied to the anterior septum and the lower turbinate. ${ }^{18}$

Studies with injection of botulinum toxin in other places for different conditions have shown variable adverse effects, in some cases severe. ${ }^{11}$ Nevertheless, botulinum toxin has been shown to be very safe for nasal use, both topically and injectable septal or in the turbinates, with no significant adverse effects reported in any of the studies. The main adverse effects described were mild epistaxis and nasal dryness. In the present study, we observed only mild burning sensation at the time of application (4 subjects) and mild, self-limited bleeding (2 subjects).

Apoptosis of nasal secretory glands observed in guinea pigs 10 days after receiving BTX-A and no longer after 3 months suggests a transient effect. ${ }^{26}$ Histological changes and clinical improvement show that BTX-A has some effects on the pathophysiology of idiopathic rhinitis and allergic rhinitis.

To reduce the risk of bias, we observed the limitations of previous studies. As for the route of administration, we opted for the injectable method for better control of the therapeutic dose when compared to topical administration with soaked sponges. In addition, the topical route requires a higher dose of BTX-A, which is a relatively expensive medication. We tried to match the control group as precisely as possible, using the same type of syringe and needle, with the same volume, injecting in the same places. Furthermore, both the patient and the professional who applied the injection were blinded to 
the contents of the syringes. The follow-up time was 12 weeks, longer than most previous studies, to try to better estimate the duration of the effect of BXT-A. The limitation of the present study is regarding the randomization process. We used simple randomization to divide the groups, which is a method that has some limitations. ${ }^{27}$ Block randomization, computer-generated randomization list, or a randomized numbers' list to divide the research groups is more advisable. ${ }^{27}$ Despite the difference between the groups in terms of gender, it was not a significant factor in determining the scores of the groups.

\section{Conclusion}

The injection of botulinum toxin in the inferior turbinates of patients with idiopathic rhinitis reduces the symptoms of sneezing, pruritus, nasal obstruction, and runny nose, with no significant adverse effects, suggesting that it is an option in the treatment of these patients. However, further studies are needed to assess the type of toxin to be used (since BTX-D has a greater effect on the neuro glandular junction), form of application (topical or injectable), local (middle, inferior, or septal turbinate), dose, and what would be the expected effects (runny nose, obstruction, itching, sneezing).

Conflict of Interests

The authors have no conflict of interests to declare.

\section{References}

1 Bousquet J, Khaltaev N, Cruz AA, et al; World Health Organization GA(2)LEN AllerGen. Allergic Rhinitis and its Impact on Asthma (ARIA) 2008 update (in collaboration with the World Health Organization, GA(2)LEN and AllerGen). Allergy 2008;63 (Suppl 86):8-160. Doi: 10.1111/j.1398-9995.2007.01620.x

2 Sakano E, Solé D, Cruz ÁA, et al.IV Consenso Brasileiro sobre Rinites 2017. Doc conjunto da Assoc Bras Alerg e Imunol Assoc Bras Otorrinolaringol e Cir Cérvico-Facial e Soc Bras Pediatr. 2017: 1-43http://www.aborlccf.org.br/secao.asp?s=3

3 Hellings PW, Klimek L, Cingi C, et al. Non-allergic rhinitis: Position paper of the European Academy of Allergy and Clinical Immunology. Allergy 2017;72(11):1657-1665. Doi: 10.1111/all.13200

4 Fokkens W, Hellings P, Segboer C. Capsaicin for Rhinitis. Curr Allergy Asthma Rep 2016;16(08):60. Doi: 10.1007/s11882-0160638-1

5 Bernstein JA, Singh U. Neural abnormalities in nonallergic rhinitis. Curr Allergy Asthma Rep 2015;15(04):18. Doi: 10.1007/s11882015-0511-7

6 Baroody FM. Nonallergic Rhinitis: Mechanism of Action. Immunol Allergy Clin North Am 2016;36(02):279-287. Doi: 10.1016/j. iac.2015.12.005

7 Segboer CL, Holland CT, Reinartz SM, et al. Nasal hyper-reactivity is a common feature in both allergic and nonallergic rhinitis. Allergy 2013;68(11):1427-1434. Doi: 10.1111/all.12255

8 Bernstein JA, Hastings L, Boespflug EL, Allendorfer JB, Lamy M, Eliassen JC. Alteration of brain activation patterns in nonallergic rhinitis patients using functional magnetic resonance imaging before and after treatment with intranasal azelastine. Ann Allergy Asthma Immunol 2011;106(06):527-532. Doi: 10.1016/j.anai.2011.02.014

9 Gevorgyan A, Segboer C, Gorissen R, van Drunen CM, Fokkens W. Capsaicin for non-allergic rhinitis. Cochrane Database Syst Rev 2015; 2015(07):CD010591. Doi: 10.1002/14651858.CD010591.pub2
10 Marshak T, Yun WK, Hazout C, Sacks R, Harvey RJ. A systematic review of the evidence base for vidian neurectomy in managing rhinitis. J Laryngol Otol 2016;130(Suppl 4):S7-S28. Doi: 10.1017/ S0022215116008008

11 Yiannakopoulou E. Serious and long-term adverse events associated with the therapeutic and cosmetic use of botulinum toxin. Pharmacology 2015;95(1-2):65-69. Doi: 10.1159/000370245

12 Awan KH. The therapeutic usage of botulinum toxin (Botox) in noncosmetic head and neck conditions - An evidence based review. Saudi Pharm J 2017;25(01):18-24. Doi: 10.1016/j.jsps.2016.04.024

13 Zhang EZ, Tan S, Loh I. Botolinum toxin in rhinitis: Literature review and posterior nasal injection in allergic rhinitis. Laryngoscope 2017;127(11):2447-2454. Doi: 10.1002/lary.26616

14 Mello JF Jr, Mion O. Rinite Alérgica. In: Campos CAH, Costa HO de O, eds. Tratado de Otorrinolaringologia. Sociedade Brasileira de Otorrinolaringología, Vol. 3 1st ed. São Paulo: Roca; 2002:68-87

15 Clement PAR, Gordts FStandardisation Committee on Objective Assessment of the Nasal Airway, IRS, and ERS. Consensus report on acoustic rhinometry and rhinomanometry. Rhinology 2005;43 (03):169-179https://pubmed.ncbi.nlm.nih.gov/16218509/. Accessed October 26, 2020

16 Kim KS, Kim SS, Yoon JH, Han JW. The effect of botulinum toxin type A injection for intrinsic rhinitis. J Laryngol Otol 1998;112 (03):248-251. Doi: 10.1017/S0022215100158281

17 Augusto AGLBS, Bussolotti Filho I, Dolci JEL, König Júnior B. Structural and ultrastructural study of the anterior portion of the nasal septum and inferior nasal concha. Ear Nose Throat J 2001;80(05):325-327, 333-338http://www.ncbi.nlm.nih.gov/ pubmed/11393913. Accessed December 7, 2017

18 Abtahi SM, Hashemi SM, Abtahi SH, Bastani B. Septal injection in comparison with inferior turbinates injection of botulinum toxin $\mathrm{A}$ in patients with allergic rhinitis. J Res Med Sci 2013;18(05):400-404

19 Yang TY, Jung YG, Kim YH, Jang TY. A comparison of the effects of botulinum toxin A and steroid injection on nasal allergy. Otolaryngol Head Neck Surg 2008;139(03):367-371. Doi: 10.1016/j. otohns.2008.06.031

20 Rohrbach S, Junghans K, Köhler S, Laskawi R. Minimally invasive application of botulinum toxin $A$ in patients with idiopathic rhinitis. Head Face Med 2009;5(01):18. Doi: 10.1186/1746-160X-5-18

21 Rohrbach S, Laskawi R. Minimally invasive application of botulinum toxin type A in nasal hypersecretion. ORL J Otorhinolaryngol Relat Spec 2001;63(06):382-384. Doi: 10.1159/000055778

22 Ünal M, Sevim S, Doğu O, Vayisoğlu Y, Kanik A. Effect of botulinum toxin type $A$ on nasal symptoms in patients with allergic rhinitis: a double-blind, placebo-controlled clinical trial. Acta Otolaryngol 2003;123(09):1060-1063. Doi: 10.1080/00016489.2003.11720744

23 Özcan C, Vayisoglu Y, Doğu O, Görür K. The effect of intranasal injection of botulinum toxin $\mathrm{A}$ on the symptoms of vasomotor rhinitis. Am J Otolaryngol 2006;27(05):314-318. Doi: 10.1016/j. amjoto.2006.01.008

24 Sapci T, Yazici S, Evcimik MF, et al. Investigation of the effects of intranasal botulinum toxin type $A$ and ipratropium bromide nasal spray on nasal hypersecretion in idiopathic rhinitis without eosinophilia. Rhinology 2008;46(01):45-51http://www.ncbi. nlm.nih.gov/pubmed/18444492 Accessed December 7, 2017

25 Hashemi SM, Okhovat A, Amini S, Pourghasemian M. Comparing the effects of Botulinum Toxin- $A$ and cetirizine on the treatment of allergic rhinitis. Allergol Int 2013;62(02):245-249. Doi: 10.2332/allergolint.12-OA-0510

26 Rohrbach S, Olthoff A, Laskawi R, Giefer B, Götz W. Botulinum toxin type A induces apoptosis in nasal glands of guinea pigs. Ann Otol Rhinol Laryngol 2001;110(11):1045-1050. Doi: 10.1177/0003489 40111001110

27 Kim J, Shin W. How to do random allocation (randomization). Clin Orthop Surg 2014;6(01):103-109. Doi: 10.4055/cios.2014.6.1.103 